\title{
Effect of dietary fat source on fatty acid profile and lipid oxidation of eggs
}

\author{
E.J. King ${ }^{3}$, A. Hugo ${ }^{2}$, F.H. de Witt ${ }^{1 \#}$, H.J. van der Merwe ${ }^{1}$ \& M.D. Fair ${ }^{1}$ \\ ${ }^{1}$ Department of Animal, Wildlife and Grassland Science and ${ }^{2}$ Department of Microbial, Biochemical and Food \\ Biotechnology, PO Box 399, University of the Free State, Bloemfontein 9300, South Africa \\ ${ }^{3}$ Nutri Feeds, PO Box 52, Viljoenskroon, 9520, South Africa
}

Copyright resides with the authors in terms of the Creative Commons Attribution 2.5 South African Licence. See: http://creativecommons.org/licenses/by/2.5/za/

Condition of use: The user may copy, distribute, transmit and adapt the work, but must recognise the authors and the South African Journal of Animal Science

\begin{abstract}
This study investigated the effects of supplementary dietary lipid sources on the fatty acid profile and lipid oxidation of eggs. Five isoenergetic (12.6 MJ AME/kg DM) and isonitrogenous (170 g CP/kg DM) diets were formulated, using a control diet ( $50: 50$ blend of fish- and linseed oil), fish oil, sunflower oil, high oleic acid (HO) sunflower oil and tallow at a $30 \mathrm{~g} / \mathrm{kg}$ inclusion level. Two hundred individually caged HyLine Silver-Brown hens (20 weeks of age) were randomly allocated to the five dietary treatments ( $\mathrm{n}=40$ hens/treatment). Birds received the experimental diets from 20 weeks of age. At 30 weeks of age, 12 eggs per treatment were randomly selected for analyses of egg yolk fatty acid methyl esters (FAME), thiobarbituric acid reactive substances (TBARS) and peroxide values (PV). Dietary lipid sources affected FAME, TBARS and PV of egg yolk significantly. The fish oil treatment resulted in the highest TBARS $(0.27$ mg malonaldehyde/kg yolk) and PV (3.96 milli-equivalent peroxide/kg fat) whereas the HO sunflower oil resulted in the lowest TBARS (0.13 mg malonaldehyde/kg yolk) and PV (2.77 milli-equivalent peroxide/kg fat). Fish oil also resulted in the lowest n-6 to n-3 ratio (1.16 to 1), while sunflower oil resulted in the highest ratio (24.6 to 1). Results indicate that the fatty acid profile of eggs could be altered by means of dietary intervention. However, an improvement of omega-3 type fatty acids of eggs will result in a higher susceptibility to lipid oxidation and possibly a shorter shelf-life of stored eggs.
\end{abstract}

Keywords: Fish oil, high oleic sunflower oil, linseed oil, percentage yolk fat, peroxide value, tallow

${ }^{\#}$ Corresponding author: dewittfh@ufs.ac.za

\section{Introduction}

Eggs are one of the most complete foods, yet the industry is being put under severe pressure, largely due to controversial reports regarding its cholesterol content (Basmacioglu et al., 2003). However, Simopoulos (2000) illustrated that cardiovascular diseases are more related to the fatty acid composition of the specific food source, rather than the cholesterol content itself. Koutsos (2007) reported that the fatty acid profile of eggs can be enriched between five- to thirty folds, without any negative effect on egg quality and/or production performances, depending on the type of fatty acids fed to the hens. Furthermore, Jiang et al. (1991) concluded that unsaturated dietary lipid sources could reduce the cholesterogenic effect of eggs by altering the fatty acid composition and incorporating more omega- 3 and omega- 6 type fatty acids into egg yolk. Furthermore, Cachaldora et al. (2008) reported that the dietary inclusion of linseed oil and fish oil would result in a linear increase in the $\alpha$-linolenic-, eicosapentaenoic-, docosapentaenoic- and docosahexaenoic acid concentrations of egg yolk, depending on dietary lipid inclusion levels.

However, increases in the polyunsaturated fatty acid (PUFA) content of eggs by means of omega-3 fatty acid enrichment would also result in an increased susceptibility to lipid oxidation. This could affect egg quality negatively, mainly due to a decrease in organoleptic properties of eggs, decreasing consumer acceptability toward "enriched" products (Hargis \& Van Elswyk, 1991). Additionally, Dunn-Hurrocks et al. (2011) reported that using dietary fish- and flaxseed oil in layer diets to manipulate the fatty acid profile of eggs resulted in higher $(P<0.01)$ thiobarbituric acid reactive substances (TBARS) with a consequent 
negative impact on the egg quality and its shelf-life. It seems that factors such as lipid source and inclusion levels (Scheideler \& Froning, 1996), as well as bird age and genotype (Schneider et al., 1990), could influence the metabolic efficiency of dietary fatty acids into egg yolk fatty acids. The divergent information in terms of lipid sources and inclusion levels, as well as their effects on the oxidation stability of endproducts produced (eggs), clearly indicates the need for more research.

The aim of this study was to investigate the effects of supplementary dietary lipid sources on the fatty acid profile and lipid oxidation of egg yolk.

\section{Materials and Methods}

Two hundred $(\mathrm{n}=200)$ HyLine Silver-Brown hens (20 weeks of age) were randomly divided into five dietary treatments, each consisting of 40 birds/treatment. Five isoenergetic (12.6 MJ AME/kg DM) and isonitrogenous (170 g CP/ $\mathrm{kg} \mathrm{DM}$ ) diets were formulated, consisting of deodorised fish oil (n-3 source), sunflower oil (n-6 source), high oleic acid (HO) sunflower oil (n-9 source) and tallow (saturated fatty acid source), as well as a control diet consisting of a blend (50:50) of fish- and linseed oil, at a $30 \mathrm{~g} / \mathrm{kg}$ dietary inclusion level. Diets were formulated to ensure that the calcium (39.4 g Ca/kg DM) and available phosphorus (3.2 g AvP/kg DM) content, as well as the ratio of Ca : AvP (12.3:1), were constant across treatments. Birds were housed individually in metabolic cages $\left(1600 \mathrm{~cm}^{2} /\right.$ bird $)$, while feed and water were provided ad libitum. At 30 weeks of age, 12 eggs per treatment $(\mathrm{n}=60$ in total) were randomly selected, weighed and broken-out for the separation of egg yolk from the albumen. An aliquot of the yolk was taken for analyses of fatty acid methyl esters (FAME), while the remainder of the yolk was sampled for the determination of egg lipid oxidation. Total lipid content was extracted from yolk using the method firstly described by Folch et al. (1957). Fatty acid methyl esters were prepared for gas chromatography by methylation of the extracted fat, using methanol- $\mathrm{BF}_{3}$ (Diaz et al., 2005) and were quantified using a Varian GX 3400 flame ionization GC, with a fused silica capillary column, Chrompack CPSIL 88 (100 m length, $0.25 \mathrm{~mm}$ ID, $0.2 \mu \mathrm{m}$ film thickness). Individual fatty acids identified, were expressed as a percentage of the total fatty acids present in the sample (\% FAME). To determine egg lipid oxidation, yolk samples were analysed for peroxide values (AOAC, 2000) and thiobarbituric acid reactive substances (Raharjo et al., 1992). Data were statistically analyzed using a fully randomized one-way ANOVA design. The PROC ANOVA procedures of the SAS program (SAS, 2001) was used to test for significant $(P<0.05)$ differences between treatment means, while Tukey's honest significant difference (HSD) test was used to separate treatment means.

\section{Results and Discussions}

The effect of dietary lipid source on the fat (\%) and fatty acid methyl ester concentration (FAME \%) of egg yolk is presented in Table 1. Dietary lipid source had no effect $(P=0.24)$ on the total fat content of egg yolk. These results are in agreement with Jiang et al. (1991) and Cachaldora et al. (2008) who reported that dietary lipid source and fatty acid saturation did not affect the total lipid content of egg yolk. As expected, egg yolk FAME as well as fatty acid ratios were affected $(P<0.0001)$ by dietary lipid sources (Table 1). These results concur with Cachaldora et al. (2008) who found similar effects of dietary lipid source on the FAME of egg yolk. Although the effect of dietary lipid sources on the concentration of total saturated fatty acids (SFA) of egg yolks were relatively constant across treatments (varied from $34.6 \%$ to $40.3 \%)$, differences $(P<0.0001)$ in total polyunsaturated fatty acids (PUFA) of egg yolks were more noticeable between the treatments $(15.7 \%$ to $25.5 \%)$. Also, both the control $(1.51: 1)$ and fish oil $(1.16: 1)$ treatments had lower $(P<0.0001)$ n-6 to n-3 (n-6 : n-3) ratios than the other treatments. By calculating the total n-3 content of eggs $(\mathrm{mg} / \mathrm{g}$ egg), a definite distinction $(P<0.0001)$ could be made between the omega-3 enriched treatments (control and fish oil) and all other experimental treatments.

The effect of dietary lipid sources on the lipid oxidation characteristics of egg yolk, as expressed by thiobarbituric acid reactive substances (TBARS) and peroxide values (PV), are presented in Table 2. Fish oil (n-3 source) resulted in the highest TBARS $(P<0.0001)$ and peroxide values $(P<0.002)$ compared to all other lipid sources used. Additionally, the HO sunflower oil treatment resulted in the lowest $(P<0.002) \mathrm{PV}$ value (2.77 milli-equivalent peroxide/kg fat). Supportive to the results of the present study, Dunn-Hurrocks et al. (2011) also reported higher $(P<0.01)$ TBARS in egg yolks from hens fed fish oil compared to 
Table 1 The mean fat content, fatty acid content and fatty acid methyl esters (FAME) content and fatty acid ratios of egg yolk as affected by dietary lipid sources

\begin{tabular}{|c|c|c|c|c|c|c|}
\hline & Control & Fish oil & Sunflower oil & $\begin{array}{c}\mathrm{HO}^{1} \\
\text { sunflower } \\
\text { oil }\end{array}$ & Tallow & $\begin{array}{c}\text { Significance } \\
(P)\end{array}$ \\
\hline Egg yolk fat content (\%) & 31.28 & 30.51 & 30.35 & 31.45 & 30.98 & $\mathrm{NS}^{2}$ \\
\hline \multicolumn{7}{|l|}{ FAME (\% of total fatty acids) } \\
\hline C16:0 & $26.66^{\mathrm{b}}$ & $30.00^{\mathrm{a}}$ & $26.67^{\mathrm{b}}$ & $25.59^{\mathrm{b}}$ & $26.52^{\mathrm{b}}$ & $<0.0001$ \\
\hline C18:0 & $10.16^{\mathrm{ab}}$ & $9.51^{\mathrm{bc}}$ & $11.29^{\mathrm{a}}$ & $8.61^{\mathrm{c}}$ & $10.04^{\mathrm{ab}}$ & $<0.0001$ \\
\hline C18:1c9 & $34.64^{\mathrm{c}}$ & $31.91^{\mathrm{c}}$ & $33.06^{\mathrm{c}}$ & $44.80^{\mathrm{a}}$ & $41.82^{\mathrm{b}}$ & $<0.0001$ \\
\hline C18:2c9,12 (n-6) & $12.71^{\mathrm{b}}$ & $11.03^{\mathrm{d}}$ & $20.41^{\mathrm{a}}$ & $12.25^{\mathrm{bc}}$ & $11.58^{\mathrm{cd}}$ & $<0.0001$ \\
\hline C18:3c9,12,15 (n-3) & $2.42^{\mathrm{a}}$ & $0.22^{\mathrm{b}}$ & $0.14^{\mathrm{b}}$ & $0.12^{\mathrm{b}}$ & $0.16^{\mathrm{b}}$ & $<0.0001$ \\
\hline $\mathrm{C} 20: 2 \mathrm{c} 11,14(\mathrm{n}-6)$ & $0.10^{\mathrm{c}}$ & $0.08^{\mathrm{c}}$ & $0.26^{\mathrm{a}}$ & $0.13^{\mathrm{b}}$ & $0.10^{\mathrm{bc}}$ & $<0.0001$ \\
\hline C20:3c11,14,17 (n-3) & $0.16^{\mathrm{bc}}$ & $0.14^{\mathrm{c}}$ & $0.24^{\mathrm{a}}$ & $0.16^{\mathrm{bc}}$ & $0.20^{\mathrm{ab}}$ & $<0.0001$ \\
\hline $\mathrm{C} 20: 4 c 5,8,11,14(n-6)$ & $1.23^{\mathrm{c}}$ & $1.00^{\mathrm{c}}$ & $3.71^{\mathrm{a}}$ & $2.77^{\mathrm{b}}$ & $2.75^{\mathrm{b}}$ & $<0.0001$ \\
\hline $\mathrm{C} 20: 5 \mathrm{c} 5,8,11,14,17(\mathrm{n}-3)$ & $0.54^{\mathrm{b}}$ & $0.95^{\mathrm{a}}$ & $\mathrm{ND}^{3}$ & $\mathrm{ND}^{3}$ & $\mathrm{ND}^{3}$ & $<0.0001$ \\
\hline C22:5c7,10,13,16,19 (n-3) & $0.56^{\mathrm{b}}$ & $0.90^{\mathrm{a}}$ & $\mathrm{ND}^{3}$ & $\mathrm{ND}^{3}$ & $0.08^{\mathrm{c}}$ & $<0.0001$ \\
\hline C22:6c4,7,10,13,16,19 (n-3) & $5.76^{\mathrm{b}}$ & $8.33^{\mathrm{a}}$ & $0.66^{\mathrm{c}}$ & $0.65^{\mathrm{c}}$ & $0.88^{\mathrm{c}}$ & $<0.0001$ \\
\hline SFA & $37.40^{\mathrm{b}}$ & $40.33^{\mathrm{a}}$ & $38.35^{\mathrm{ab}}$ & $34.64^{\mathrm{c}}$ & $37.43^{\mathrm{b}}$ & $<0.0001$ \\
\hline MUFA & $39.13^{\mathrm{b}}$ & $37.03^{\mathrm{b}}$ & $36.15^{\mathrm{b}}$ & $49.23^{\mathrm{a}}$ & $46.83^{\mathrm{a}}$ & $<0.0001$ \\
\hline PUFA & $23.47^{\mathrm{b}}$ & $22.64^{\mathrm{b}}$ & $25.50^{\mathrm{a}}$ & $16.14^{\mathrm{c}}$ & $15.74^{\mathrm{c}}$ & $<0.0001$ \\
\hline \multicolumn{7}{|l|}{ Fatty acid ratios } \\
\hline PUFA / SFA & $0.63^{\mathrm{a}}$ & $0.56^{\mathrm{b}}$ & $0.67^{\mathrm{a}}$ & $0.47^{\mathrm{c}}$ & $0.42^{\mathrm{d}}$ & $<0.0001$ \\
\hline$n-6 / n-3$ & $1.51^{\mathrm{d}}$ & $1.16^{\mathrm{d}}$ & $24.60^{\mathrm{a}}$ & $17.22^{\mathrm{b}}$ & $11.90^{\mathrm{c}}$ & $<0.0001$ \\
\hline mg n-3 / g egg & $7.26^{\mathrm{a}}$ & $7.78^{\mathrm{a}}$ & $0.73^{\mathrm{b}}$ & $0.74^{\mathrm{b}}$ & $0.95^{\mathrm{b}}$ & $<0.0001$ \\
\hline
\end{tabular}

a,b,c,d Row means with different superscripts differ significantly $(P<0.0001) ;{ }^{1}$ High oleic acid sunflower oil;

${ }^{2} \mathrm{NS}$ - not significant $(P>0.05) ;{ }^{3} \mathrm{ND}$ - not detected.

SFA: total saturated fatty acids; MUFA: total monounsaturated fatty acids; PUFA: total polyunsaturated fatty acids.

Table 2 The mean $( \pm$ SD) thiobarbituric acid reactive substances and peroxide value of egg yolk as affected by dietary lipid source

\begin{tabular}{lcccccc}
\hline & Control & Fish oil & $\begin{array}{c}\text { Sunflower } \\
\text { oil }\end{array}$ & $\begin{array}{c}\mathrm{HO}^{1} \\
\text { sunflower } \\
\text { oil }\end{array}$ & Tallow & $\begin{array}{c}\text { Significanc } \\
\mathrm{e}(P)\end{array}$ \\
\hline $\begin{array}{l}\text { Thiobarbituric acid reactive } \\
\text { substances } \\
\text { (mg malonaldehyde/kg yolk) }\end{array}$ & $0.19^{\mathrm{b}} \pm 0.05$ & $0.27^{\mathrm{a}} \pm 0.09$ & $0.16^{\mathrm{b}} \pm 0.05$ & $0.13^{\mathrm{b}} \pm 0.04$ & $0.13^{\mathrm{b}} \pm 0.03$ & $<0.0001$ \\
$\begin{array}{l}\text { Peroxide value } \\
\text { (milli-equivalent peroxide/kg fat) }\end{array}$ & $3.07^{\mathrm{b}} \pm 0.64$ & $3.96^{\mathrm{a}} \pm 0.67$ & $3.53^{\mathrm{ab}} \pm 1.01$ & $2.77^{\mathrm{b}} \pm 0.45$ & $3.23^{\mathrm{ab}} \pm 0.73$ & $<0.002$ \\
\hline
\end{tabular}

\footnotetext{
a,b Row means with different superscripts differ significantly $(P<0.05)$.

1 High oleic acid sunflower oil.
}

sunflower oil. In the present study, the control diet consisting of a blend between fish- $(15 \mathrm{~g} / \mathrm{kg})$ and linseed oil $(15 \mathrm{~g} / \mathrm{kg})$ seems to resist lipid oxidation better $(P<0.002)$ than the pure fish oil $(30 \mathrm{~g} / \mathrm{kg})$ treatment. Supportive to the present findings, Hayat et al. (2010) reported that the inclusion of flaxseed in layer diets resulted in a higher oxidative stability compared to fish oil and related this improvement in oxidative 
stability to the higher levels of shorter chain omega-3 type PUFA such as $\alpha$-linolenic acid within flaxseed oil, compared to the longer chain omega-3 type PUFA such as eicosapentaenoic-, docosapentaenoic- and docosahexaenoic acid in fish oil.

\section{Conclusions}

This study has shown that it is possible $(P<0.0001)$ to alter the fatty acid profile of egg yolk without any negative effects $(P=0.24)$ on the total fat content of eggs itself. Furthermore, it seems that combination of plant (linseed oil) and fish oil would withstand lipid oxidation in egg yolk better than the dietary inclusion of pure fish oil in diets to produce omega-3 enriched eggs. Nutritionist should therefore be cautious during diet formulation for "enriched eggs" in ensuring that that use of specific lipid sources would not result in a shorter shelf-life of eggs due to an increase in lipid peroxidation.

\section{Acknowledgements}

The authors wish to acknowledge Nutri Feeds, Energy oil and Vergezocht HO oils for their technical and financial support during the trial.

\section{References}

AOAC, 2000. Official Methods of Analysis, $17^{\text {th }}$ ed. Association of Official Analytical Chemists, Virginia.

Basmacioglou, H., Cabuk, M., Unal, L.K., Ozkan, K., Akkan, S. \& Yalcin, H., 2003. Effects of dietary fish oil and flaxseed on cholesterol and fatty acid composition of egg yolk and blood parameters of laying hens. S. Afr. J. Anim. Sci. 33, 266-273.

Cachaldora, P., Garcia-Rebollar, P., Alvarez, C., De Blas, J.C. \& Mendez, J., 2008. Effect of the type and the level of fish oil supplementation on yolk fat composition and n-3 fatty acid deposition efficiency in laying hens. Anim. Feed Sci. Technol. 141, 104-114.

Diaz, M.T., Alvarez, I., De La Fuente, J., Sanudo, C., Campo, M.M., Oliver, M.A., Font i Furnols, M., Montossi, F., San Julian, R., Nute, G.R. \& Caneque, V., 2005. Fatty acid composition of meat from typical lamb production systems of Spain, U.K., Germany and Uruguay. Meat Sci. 71, 256-263.

Dunn-Hurrocks, S., Pichardo-Fuchs, M., Lee, J., Ruiz-Feria, C., Creger, C., Hyatt, D., Stringfellow, K., Sanchez, M. \& Farnell, M., 2011. Effect of omega-3 enriched layer rations on egg quality. Int. J. Poult. Sci. 10, 8-11.

Folch, J., Lees, M. \& Sloane-Stanley, G.H., 1957. A simple method for the isolation and purification of total lipids from animal tissue. J. Biol. Chem. 226, 497-509.

Hargis, P.S. \& Van Elswyk, M.E., 1991. Dietary modification of yolk lipid with menhaden oil. Poult. Sci. 70, 874-883.

Hayat, Z., Cherian, G., Pasha, T.N., Khattak, F.M. \& Jabbar, M.A., 2010. Oxidative stability and lipid components of eggs from flax-fed hens: Effect of dietary antioxidants and storage. Poult. Sci. 89, 1285-1292.

Jiang, Z., Ahn, D.U. \& Sim, J.S., 1991. Effects of feeding flax and two types of sunflower seeds on fatty acid compositions of yolk lipid classes. Poult. Sci. 70, 2467-2475.

Koutsos, E., 2007. Effects of hen nutrition on egg consumption. Feed info news service. www.feedinfo.com, accessed 8 April 2011.

Raharjo, S., Sofos, J.N.S. \& Schmidt, G.R., 1992. Improved speed specificity, and limit of determination of an aqueous acid extraction thiobarbituric acid- $\mathrm{C}_{18}$ method for measuring lipid peroxidation in beef. J. Agric. Food Chem. 40, 2182-2185.

SAS, 2001, SAS ${ }^{\circledR}$ User’s Guide. Version 6.12. SAS Institute Inc. Cary, N.C., USA.

Scheideler, S.E. \& Froning, G.W., 1996. The combined influence of dietary flaxseed level, form and storage conditions on egg production and composition among vitamin E-supplemented hens. Poult. Sci.75, 1221-1225.

Schneider, W.J., Carroll, R., Severson, D.L. \& Nimpf, J., 1990. Apolipoprotein VLDL-II inhibits lipolysis of triglyceride-rich lipoproteins in the laying hen. J. Lipid Res. 31, 507-513.

Simopoulos, A.P., 2000. Symposium: Role of poultry products in enriching the human diet with n-3 PUFA. Poult. Sci. 79, 961-970. 